\title{
Speed and agility as predictors of long jump performance of male athletes
}

\author{
Mukesh Kumar MISHRA, Vishan Singh RATHORE
}

Guru Ghasidas University, Department of Physical Education, Bilaspur, Chhattisgarh, India.

Address Correspondence to MK. Miasra, e-mail: mkspe88@gmail.com

\begin{abstract}
The main purpose of this study was to predict the long jump performance on the basis of speed, agility, height and weight of male athletes. 46 male athletes were participated in present study (mean \pm SD; $22.28 \pm 1.3770$ years). The selected athletes were measured of their speed by $50 \mathrm{~m}$ dash sprint test (sec.), agility measured by $4 \times 10 \mathrm{~m}$ shuttle run test (sec.) and long jump performance measured by long jump (meter). Pearson product-moment correlations revealed a significant negative correlation of Long Jump performance with speed $(\mathrm{r}=-0.813, \mathrm{p}<0.05)$, Agility $(\mathrm{r}=-0.702, \mathrm{p}<0.05)$ and weight $(\mathrm{r}=-0.343, \mathrm{p}<0.05)$. Multiple correlations revealed that joint contribution of all independent variables to estimating Long Jump performance $\left(R=.847, R^{2}=.717\right)$, which impales that $71.7 \%$ of Long Jump Performance is obtained by these variables (Weight, Height, Agility and Speed). The regression analysis (enter method) outcomes proved that long jump performance can be determined by selected independent variables $(\mathrm{F}=25.933, \mathrm{p}<0.05)$. Based on the result of present study suitable formula was determined [Long Jump performance $=5.356-.283$ (Speed) -.102 (Agility) + .021 (Height) -.019 (Weight)]. It was concluded that the formula suggested in this study, can be used to determine the long jump performance of male athletes.
\end{abstract}

Key words: Long jump performance, speed, agility, height, weight.

\section{INTRODUCTION}

The continuous scientific progression in the area of sports has made sports training more purposive, based on fact and very specific than ever. Sports scientists are leaving nothing to improve in order to find out the performance enhancing and affecting factor as well as the best outcome oriented training systems for each sport. In modern time more and more consideration has been paid to nature of physical fitness not only in terms of general healthiness but also of the particular physical requisite for competitive sports and sure highly specialized and challenging occupations. Physical fitness is an inseparable piece of sports performance and achievements. The quality of its consumption value is directly proportional to the level of performance. That means the greater level of fitness, greater the ability of a person to attain higher level of performance.

Long jump is a moving event and requires a participant to have speed, explosive leg strength as well as suitable coordination of distance, strides and bounce action of the body at take- off stage level $(22,23)$. The distance of a long jumper is influenced by some other factors; i.e. the approach run speed, the adaptation of this speed to forward and upward force at the takeoff, the range during which he can apply this forces at an most advantageous angle and the efficiency with which these factors conclude at the landing in the pit $(9,12)$. The world's best long jumpers have constantly been excellent sprinters though some without outstanding sprinting capability may become top performers if they concentrate in the event and perfect all the long jumping techniques. Specific areas to be considered in long jump are; the approach run, the take-off, the action in the air (the flight phase), and the landing (12). It is though that is important to determine the predictors of long jump performance. Therefore, the purpose of this study was to assess whether speed and agility can be used to predict long jump performance of male athletes. 


\section{MATERIAL \& METHOD}

\section{Samples}

Forty six male athletes voluntary participated in the study. These athletes were purposively selected from Department of Physical Education, Guru Ghasidas University Bilaspur, Chhattisgarh, India.

Table 1. Characteristics of subjects.

\begin{tabular}{lccc}
\hline Variables & $\mathrm{N}$ & Mean & SD \\
\hline Age & 46 & 22.28 & 1.38 \\
Height & 46 & 167.42 & 5.28 \\
Weight & 46 & 65.22 & 6.56 \\
\hline
\end{tabular}

Participants were excluded if they had any type of injuries. Before testing began, the aim and procedures of the study were explained to the participants and informed.

\section{Procedures}

All measurements were taken on the same day under the direction of researcher and supporting staffs. Subjects got an oral and visual exhibit of the best possible procedures required to effectively finish every test before they were requested that perform them. Subjects were then permitted up to 1-2 submaximal trials to practice technique. Once the submaximal trials were finished the subjects performed every test. To ensure proper recovery time, participants completed one trial at a time with at least five to ten minutes between trials. Verbal encouragement was given to all participants.

Table 2. Selected variables and their criterion measures with unit of measurements.

\begin{tabular}{lcc}
\hline Variables & Criterion measures & Unit of measures \\
\hline Age & School/college certificate & Years \\
Height & Stadiometer & Centimeter $(\mathrm{cm})$ \\
Weight & Weighing Scale & Kilogram $(\mathrm{kg})$ \\
Speed & 50 yard dash & Seconds \\
Agility & $4 \times 10 \mathrm{mt}$. shuttle run & Seconds \\
Long Jump & Long Jump & Meter $(\mathrm{m})$ \\
performance & & \\
\hline
\end{tabular}

Age

Date of birth mentioned in athlete's school or college certificates were considered as age (years) of athletes.

\section{Height and weight}

The measurements of the weight and height were done with digital weighting scale $(\mathrm{kg})$ and stadiometer $(\mathrm{cm})$.

\section{$50 \mathrm{~m}$ dash test}

Each athlete was allowed two attempts with the best time being recorded to the nearest $0.10 \mathrm{sec}$ using a crouch start position; athletes positioned themselves behind the starting line. The timer started when the 'go' command was given, and stopped after sprinting the full $50 \mathrm{~m}$ distance.

\section{$4 \times 10 \mathrm{~m}$ Shuttle run test}

Each athlete was instructed to stand behind the start line. In this test also, each athlete was allowed two attempts with the best time being recorded to the nearest $0.10 \mathrm{sec}$ using a standing start position. On the command of ' $\mathrm{go}$ ' the timer started and stopped when the athlete completed 4 shuttles of given distance $(10 \mathrm{~m})$.

\section{Long jump performance}

After the compellation speed and agility test, athletes were going for long jump performance. Long jump pit was used to conduct long jump test with proper marking and take off board. For the long jump performance each athletes were permitted to take maximum $40 \mathrm{~m}$ approach run. The athletes were free to perform any techniques of long jump. The nearest point of landing was measured from take-off board, with the help measuring tape in meters and record as the performance of athletes.

\section{Statistical analysis}

The descriptive statistics i.e. mean, standard deviation etc. were calculated for all variables. Pearson product-moment correlations were calculated to examine the relationship between variables and multiple correlations were used to joint contribution of Independent Variables in estimating Long Jump performance. Regression analysis (enter method) was used to established equation for predicting Dependent Variable (Long Jump performance) on the basis of selected Independent Variables. An alpha level of $p \leq$ 0.05 was used to determine correlation significance. All statistics were calculated with SPSS 16.0. 


\section{RESULTS}

Dependent Variable: Long Jump

The table 4 shows that standardized (std.) residual, max value (1.928) and min value (-1.875), both values doesn't exceed $+3 \&-3$. This proves that the range doesn't have any outliers.

Table 5 clearly indicates that there exists a significant relationship between dependent variable
Long Jump performance and Independent Variables i.e. Weight, Speed and Agility as the significant values were found lesser than the .05 .

On the other hand there exists an insignificant relationship between Long Jump performance andHeight as the significant value was found higher than the .05 .

Table 3. Descriptive Statistics of selected variables.

\begin{tabular}{lcccccc}
\hline Variables & $\mathrm{N}$ & Mean & SE & SD & Minimum & Maximum \\
\hline Height & 46 & 167.42 & .77921 & 5.28483 & 159.40 & 185.60 \\
Weight & 46 & 65.2200 & .96775 & 6.56362 & 52.00 & 82.10 \\
Speed & 46 & 6.7809 & .12348 & .83748 & 5.60 & 9.10 \\
Agility & 46 & 10.4987 & .13247 & .89849 & 8.70 & 12.10 \\
Long Jump & 46 & 4.7176 & .06081 & .41245 & 3.77 & 5.44 \\
\hline
\end{tabular}

Table 4. Residuals statistics for checking outliers.

\begin{tabular}{lcccc}
\hline & Mean & Std. Deviation & Maximum & Minimum \\
\hline Predicted Value & 4.7176 & .34918 & 5.2058 & 3.8559 \\
Std. Predicted Value & .000 & 1.000 & 1.398 & -2.468 \\
Residual & .00000 & .21952 & .44340 & -.43113 \\
Std. Residual & .000 & .955 & 1.928 & -1.875 \\
\hline
\end{tabular}

Histogram



Figure 1. Normality curve in relation to long jump performance of male athletes.
Normal P-P Plot of Regression Standardized Residual

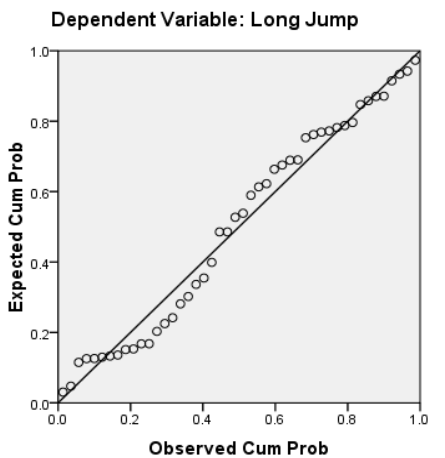

Figure 2. Normality probability plots in relation to long jump performance of male athletes.

Table 5. Correlation between dependent variable (long jump performance) and independent variables (height, weight, speed and agility).

\begin{tabular}{lccc}
\hline Variables & $\mathrm{N}$ & Correlation coefficient $(\mathrm{r})$ & Sig. value \\
\hline Height & 46 & -.034 & .411 \\
Weight & 46 & $-.343^{*}$ & .010 \\
Speed & 46 & $-.813^{*}$ & .000 \\
Agility & 46 & $-.702^{*}$ & .000 \\
\hline * Statistically significant at 0.05 level of significance. &
\end{tabular}




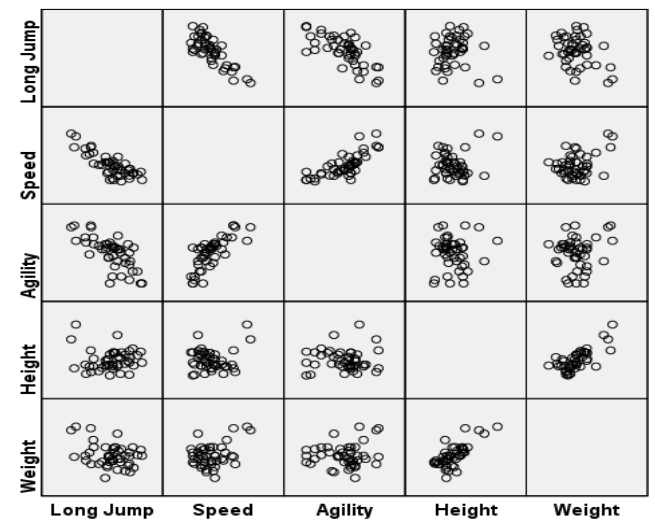

Figure 3. Matrix Scatter diagram for relationship among the selected variables.

Table 6. Model Summary showing multiple correlations between long jump performance and selected independent variables (weight, height, agility and speed).

\begin{tabular}{|c|c|c|c|c|c|c|c|c|c|}
\hline \multirow{2}{*}{ Model } & \multirow{2}{*}{$\mathrm{R}$} & \multirow{2}{*}{ R Square } & \multirow{2}{*}{$\begin{array}{l}\text { Adjusted R } \\
\text { Square }\end{array}$} & \multirow{2}{*}{$\begin{array}{l}\text { Std. Error of } \\
\text { the Estimate }\end{array}$} & \multicolumn{5}{|c|}{ Change Statistics } \\
\hline & & & & & $\begin{array}{l}\text { R Square } \\
\text { Change }\end{array}$ & F Change & df1 & df2 & $\begin{array}{l}\text { Sig. F } \\
\text { Change }\end{array}$ \\
\hline 1 & $.847 a$ & .717 & .689 & .22998 & .717 & 25.933 & 4 & 41 & .000 \\
\hline
\end{tabular}

Table 7. The ANOVA table of the linear regression model in relation to long jump performance on the basis of selected independent variables (weight, height, agility and speed).

\begin{tabular}{|c|c|c|c|c|c|c|}
\hline Model & & Sum of Squares & Df & Mean Square & $\mathrm{F}$ & Sig. \\
\hline \multirow{3}{*}{1} & Regression & 5.487 & 4 & 1.372 & & \\
\hline & Residual & 2.169 & 41 & .053 & 25.933 & $.000 \mathrm{a}$ \\
\hline & Total & 7.655 & 45 & & & \\
\hline
\end{tabular}

Dependent Variable: Long Jump performance

In table 6 we can see the multiple correlation between Long Jump performance and selected independent variables (Weight, Height, Agility and Speed) is given $(\mathrm{R}=.847)$. $\mathrm{R}$ Square is .717 , which impales that $71.7 \%$ of Long Jump Performance is obtained by these variables (Weight, Height, Agility and Speed).

\section{Dependent Variable: Long Jump}

The above ANOVA table (table 7) shows that the usefulness of the linear regression model. This model has found useful in estimating the Long Jump performance on the basis of selected independent variables i.e. Weight, Agility, Height, Speed, since F value $(25.933)$ has found significant $(p<0.05)$.

Dependent Variable: Long Jump

Table 8 shows that the quantification of relationship between selected independent variables
(Speed, Agility, Height, and Weight) and Long Jump performance, with increases of every one unit of Speed, Agility, Height and Weight. The Long Jump performance (on the average) increases by $-.283,-.102$, .021 and -.019 units respectively. The constant 5.356 gives the value of Long Jump performance when these variables (Speed, Agility, Height and Weight) are equal zero (0).

Regression model for estimating Long Jump performance on the basis of selected variables

Model 1: $Y=5.356-.283\left(X_{1}\right)-.102\left(X_{2}\right)+.021\left(X_{3}\right)-$ $.019\left(\mathrm{X}_{4}\right)$

Where: $\mathrm{Y}=$ Long Jump performance, $\mathrm{X}_{1}=$ Speed, $X_{2}=$ Agility, $X_{3}=$ Height, $X_{4}=$ Weight .

So the regression model is:

Long Jump performance $=5.356-.283$ (Speed) .102 (Agility) + .021 (Height) -.019 (Weight) 


\begin{tabular}{|c|c|c|c|c|c|c|}
\hline & \multirow{2}{*}{ Model } & \multicolumn{2}{|c|}{ Unstandardized Coefficients } & \multirow{2}{*}{$\frac{\text { Standardized Coefficients }}{\text { Beta }}$} & \multirow{2}{*}{$\mathrm{t}$} & \multirow{2}{*}{ Sig. } \\
\hline & & B & Std. Error & & & \\
\hline \multirow{5}{*}{1} & (Constant) & 5.356 & 1.380 & & 3.881 & .000 \\
\hline & Speed & -.283 & .070 & -.574 & -4.022 & .000 \\
\hline & Agility & -.102 & .061 & -.223 & -1.674 & .102 \\
\hline & Height & .021 & .010 & .274 & 2.220 & .032 \\
\hline & Weight & -.019 & .008 & -.301 & -2.258 & .029 \\
\hline
\end{tabular}

\section{DISCUSSION}

The purpose of the present study was to examine relationships of Long Jump performance with speed, agility, height and weight in male athletes. The main finding is that there are significant relationships of Long Jump performance with speed, agility and weight. Posting a good time in sprint tests requires the ability to generate enough force to start quickly and reach maximum velocity early in the sprint (5). Long jump is a measure of force and power production and appears to be related to sprint distances of five to 40 yards (3). Many authors have found a relationship between various measures of sprint and jump performance. That relationship might be explained by the similar conducted by Brechue et al. (3) and the present study. They also found the Long-jump distance correlated significantly with velocity, power and power relative to body weight. Seiler and colleagues (24)reported a strong correlation between standing long jump and increasing rate of sprint. Barr and Nolte (2)found a significant correlation between jump performance and $10 \mathrm{~m}$ sprint. McCurdy and colleagues (13)also observed a significant relationship between 40 -yard velocity and long jump in women soccer players. The results of the present study are in agreement with past studies and appear to confirm the relationship $(r=-.813$, $\mathrm{p}<.0 .05)$ between Long Jump performance and sprinting. Therefore, athletes would benefit from exercises that promote both speed and power to improve performance.

Agility is reported to be a multi factorial physical ability affected by strength, speed, balance, flexibility, and muscular coordination (4). These findings of the present study show significant correlations ( $\mathrm{r}=-.702$, $\mathrm{p}<.0 .05)$ among Long Jump performance and agility. Related results showed by Koklu et al. (10)found significant correlations between CMJ and zigzag agility test in soccer players. Chaouachi et al. (4) reported a significant negative correlation between TT and jump test performance in elite male ( 23 years old) basketball players. In a recent study conducted by Alemdaroglu (1), he concluded that a significant correlation between CMJ and TT (in professional men (25 years old) basketball players.

As we know the long jump, speed ability and agility are the dynamic movements and these performances to be closely related. The event of Long jump can be classified into different phases namely the approach run, take off, flying phase and landing. The straight distance jumped by the athlete depends on the athlete's speed during the approach run and the takeoff force created by the jumper to convert the horizontal momentum into angular momentum and also marvelous amount of agility and flexibility overcome by the jumper for performing the movement at different joint and large amplitude, mainly while executing the takeoff phase. So maybe it is a possible reason for these findings. Another justification for the high relationship between speed, agility and Long jump performance may be the same energy systems that each movement type demands. None of the tests kept going more than 10-12 seconds, and hence the phosphagen system (ATP-PC) contributed to the energy demand for all of them.

In conclusions, on the basis of result and findings these following conclusions can be drawn:

* Significant relationship was found between Long Jump performance and Weight $(\mathrm{r}=-.343, \mathrm{p}<.05)$.

* Significant relationship was found between Long Jump performance and speed $(\mathrm{r}=-.813, \mathrm{p}<.05)$.

* Significant relationship was found between Long Jump performance and Agility $(\mathrm{r}=-.702, \mathrm{p}<.05)$.

* Insignificant relationship was found between Long Jump performance and Height $(\mathrm{r}=-.034, \mathrm{p}$ $>$.05).

* Multiple Relationship (R) between Long Jump performance and selected Independent variables (Weight, speed, Agility, Height) is $\mathrm{R}=0.847$ and $\mathrm{R}$ square is 0.717 , which shows that $71.7 \%$ of Speed 
is obtained by these four independent variables i.e. Weight, speed, Agility, Height.

* Regression equation Long Jump performance = $5.356-.283$ (Speed) -.102 (Agility) + .021 (Height) .019 (Weight), was found fructiferous in estimating Long Jump performance on the basis of selected Variables(Weight, speed, Agility, Height).

\section{REFERENCES}

1. Alemdaroglu U. The relationship between muscle strength, anaerobic performance, agility, sprint ability and vertical jump performance in professional basketball players. J Hum Kin, 2012; 31: 99-106.

2. Barr MJ, Nolte VW. Which measure of drop jump performance best predicts sprinting speed? J Strength Cond Res, 2011; 25: 1976-1982.

3. Brechue, WF, Mayhew JL, Piper FC. Characteristics of sprint performance in college football players. Journal of Strength and Conditioning Research, 2010; 24(5): 1169- 1178.

4. Chaouachi A, Brughelli M, Chamari K, Levin GT, Ben Abdelkrim N, Laurencelle L, Castagna, C. Lower limb maximal dynamic strength and agility determinants in elite basketball players. J Strength Cond Res, 2009; 23: 1570-1577.

5. Cronin JB, Hansen KT. Strength and power predictors of sports speed. Journal of Strength and Conditioning Research, 2005; 19(2): 349-357.

6. Davis K, Rossi S, Langdon J, McMillan J. The relationship between jumping and sprinting performance in Collegiate Ultimate Athletes. Journal of Coaching Education, 2012; 5(2): 24-92.

7. Goran S, et. al. The effect of agility training on athletic power performance. Kinesiology, 2010; 42(1): 65-72.

8. Harold M, Barrow McGee R. A Practical Approach to Measurement in Physical Education, Philadelphia: Lea and Febiger, 1971: 123.

9. Hubbard, M., The flight of sports projectiles, In V. M. Zatsiorsky (Ed.), Biomechanics in sport. Oxford: Blackwell Science, 2001: 381-400.

10. Koklu Y, Alemdaroglu U, Ozkan A, Koz M, Ersoz G. The relationship between sprint ability, agility and vertical jump performance in young soccer players. Sci Sport, 2015; 30: e1-e5.

11. Linthorne NP, Guzman MS, anBridgett LA. Optimum take-off angle in the long jump, Journal of Sports Sciences, 2005; 23: 703$712,359-372$.

12. Linthorne NP. Optimum release angle in the shot put. Journal of Sports Sciences, 2001; 19.

13. McCurdy KW, Walker JL, Langford GA,Kutz MR, Guerrero JM, McMillan J. The relationship between kinematic determinants of jump and sprint performance in division I women soccer players. Journal of Strength and Conditioning Research, 2010; 24(12): 3200-3208.

Turk ل Sport Exe 2016; 18(2): 27-33

( 2016 Faculty of Sport Sciences, Selcuk University
14. Meena TR, Choudhary R. Estimation of lean body maas on the basis of vertical jump, weight, vital capacity, in-breath chest circumference, Proceedings of International Conference on Physical Activities and Sports for Global Peace and Development. IGIPESS: New Delhi, 2011: 121-124.

15. Meena TR, Mishra MK. Prediction of Gymnastic Performance on the Basis of Selected Physical Fitness Components. Academic Sports Scholar, 2015; 4 (6): 1-7.

16. Milanese C, Bortolami O, Bertucco M, Verlato G, Zancanaro C. Anthropometry and Motor fitness in children aged 6-12 years, Jurnal of Human Sporta and Exercise, 2010; 1.5(2): 265-279.

17. Mishra MK, Choudhary R. Estimation of raider's performance on the basis of reaction ability in kabaddi. Global excellence in fitness and sports science, twenty century publication: Patiala, 2015; 2: 159-164.

18. Mishra MK, Rathore VS. Anthropometric variables as predictors of speed ability of physical education students. International Journal of Physical Education, Sports and Health, 2016; 3(1): 140-144.

19. Mishra MK, Rathore VS. Selected Anthropometric Parameters as a Predictors of Volleyball Playing Ability. International Journal of Science and Research, 2015; 4(9): 436-439.

20. Mishra MK, Thakur JS. An Estimation of Kho-Kho Performance on the Basis of Selected Physical Fitness Parameters. International Journal of Sports Sciences and Fitness, 2015; 5(2): 235-250.

21. Mishra MK. A comparative study of speed ability between high and low achievers male hockey players. Academic Sports Scholar, 2014; 3(9): 1-3.

22. Ngetich EDK. Assessment of Physical Fitness Components as Predication factors of Long Jump performance among female undergraduate students of Indira Gandhi Institute of Physical Education and Sports Sciences - Delhi University. Unpublished M.P.Ed Thesis. Delhi University, New Delhi, India, 1998.

23. Renwick GR. Play Better Athletics, Delhi: sports Publication, 2001.

24. Seiler S, Taylor M, Diana R, Layes J, Newton P, Brown. Assessing anaerobic power in collegiate football players. Journal of Applied Sport Science Research, 1990; 4(1): 9- 15.

25. Sharma HO, Subramanian R. Speed and Agility as determinants of Long Jump Performance, Academic Sports Scholar, 2014; 3(9): 49-52.

26. Singh MK. Analytic study of coordinative abilities in fundamental skills of basketball players. International journal of physical education, sports and yogic sciences, 2012; 2(1): 44-46.

27. Singh VK, Singh R. Physical, Physiological, Psychological and Anthropometric Variables as Predictors for Speed of Sub-Junior Athletes. Academic Sports Scholar, 2014; 3 (8): 1-4.

28. Sohi AS. A study of development of speed and agility among 6 - 14 years of boys and girls. Snipes Journal, 1986; 9(3): 16-23. 
29. Thakur JS, Mishra MK, Rathore VS. Impact of plyometric training and weight training on vertical jumping ability. Turkish Journal of Sports and Exercise, 2016; 18(1): 31-37.

30. Veligekas P, Tsoukos A, Bogdanis GC. Determinants of standing long jump performance in 9-12 year old children. Serbian Journal of Sports Sciences, 2012; 6(4): 147-155.
31. Verma JP. Sports statistics. Gwalior: Venus Publications, 2000.

32. Zapartdis I, Vareltizis I, Gouvali M. Kororos P. Physical fitness and anthropometric characteristics in different levels of young team handball players. The Open Sport Sciences Journal, 2009; 2: $22-28$. 